\title{
ARTIGO
}

\section{CENAS DE LEITURA DA CIÊNCIA HOJE DAS CRIANCASA: MODOS DE USO E APROPRIAC̦ÃO DA REVISTA EM SALA DE AULA ${ }^{1}$}

\author{
Sheila Alves de Almeida" \\ Universidade Federal de Ouro Preto (UFOP), Ouro Preto - MG, Brasil
}

RESUMO: Este trabalho trata dos modos de uso e apropriação da revista Ciência Hoje das Crianças em uma turma de séries iniciais do Ensino Fundamental. A perspectiva teórico-metodológica de análise inspira-se nas concepções de Bakhtin e Vygotsky acerca da interação verbal e na "memória pedagógica" sobre os acontecimentos de sala de aula. As análises apontam que o uso da revista Ciência Hoje das Crianças em sala de aula faz circular a linguagem de divulgação científica. Ressalta-se, a importância da revista nas aulas de Ciências dado o nível de envolvimento das crianças e da professora, a aprendizagem de conteúdos de ciências e a qualidade da participação de todos durante a experiência pedagógica com o periódico. Entretanto, essa postura não é construída espontaneamente e está relacionada, entre outras coisas, ao acesso à revista na sala de aula e à forma como as atividades de ensino foram conduzidas pela professora.

Palavras-chave: Letramento. Divulgação científica. Ensino de Ciências.

\section{READING CIÊNCIA HOJE DAS CRIANÇAS: THE MAGAZINE'S USAGE MODES AND OWNERSHIPIN CLASSROOM}

ABSTRACT: This work deals with usage modes and magazine ownership of Ciência Hoje das Crianças in an elementary school's early grade class. Theoretical and methodological perspective analysis are inspired by Bakhtin and Vygotsky's conceptions of verbal interaction and "educational memory" in classroom events. The analysis indicates that using Ciência Hoje das Crianças in classroom helps circulate science communication language. It emphasizes the magazine's importance in Science classes, given the level of involvement of children and teacher, learning scientific content and the quality of participation of all during pedagogical experience with the publication. However, this attitude is not built spontaneously and is related, among other things, to the access of the magazine in class and how the activities were conducted by the teacher.

Keywords: Literacy. Science communication. Science education.

\footnotetext{
"Doutora em Educação pela Universidade de São Paulo (USP). Professora pesquisadora do Programa de Pós Graduação em Educação da Universidade Federal de Ouro Preto (PPGE-UFOP).

Email: < sheilaalvez@iceb.ufop.br >.
} 


\section{INTRODUC̣ÃO}

A apropriação do gênero de divulgação científica na escola tem sido objeto de preocupação crescente de muitas pesquisas no campo da Educação (ALMEIDA, M. etal, 1998, 2000, 2001; ROJO, 2009, 2010; ALMEIDA, 2011). Antes da década de 1980, os materiais impressos para a infância estavam mais presentes na esfera doméstica, dedicados a algumas classes sociais e tinham como propósito, ocupar o tempo das crianças com atividades como colorir, recortar e colar. A década de 1980 foi marcada pelo surgimento de revistas como Ciência Hoje (1982), Galileu (1991), Super Interessante (1987) e Ilustrada, que circulou entre 1982 a 1984. No bojo desse movimento, a produção da revista Ciência Hoje das Crianças (1986), colocou luz no discurso de divulgação científica para crianças. Além das revistas especializadas, os estudos de Cunha (2009), Pinto (2007), Martins (2001) e Gouvea (2000) revelam que a década de 1980 foi fortemente marcada pelo surgimento, no Brasil, de programas de TV e rádio, livros, sites e ações diversificadas com o intuito de divulgar, com mais intensidade, a ciência para o público não especializado, atingindo o público infantil.

$\mathrm{Na}$ escola, o discurso de divulgação científica está presente nos livros didáticos, paradidáticos, literatura, jornais, revistas, textos digitais, mídia eletrônica, etc. Rojo (informação verbal) ${ }^{2}$ ao discutir os "materiais didáticos no letramento escolar" avalia que a partir da segunda metade dos anos 1990 aumentou, significativamente, o número de materiais disponíveis ao professor, dentre os quais se destacam materiais cujo objetivo era divulgar a ciência. Além disso, os Parâmetros Curriculares Nacionais de 1998 pavimentaram a estrada para o trabalho com a diversidade de gêneros dentro da sala de aula. De acordo com essa autora, nas décadas anteriores, a leitura e a produção textual ficavam muito centradas nos gêneros estritamente escolares - narrativas e poemas - e a leitura era meramente para a localização de informação.

Em 2004, Rojo desenvolveu uma pesquisa para aferir as modalidades de gêneros de discurso presentes nos livros didáticos de Língua Portuguesa, mais utilizados pelos professores das escolas públicas brasileiras. Nesse estudo, analisou 43 coleções de $1^{\mathrm{a}}$ a $4^{\mathrm{a}}$ séries do Ensino Fundamental que estiveram em sala de aula, até o fim de 2009. Os textos foram categorizados por gênero, esfera de produção e âmbitos de atuação. De acordo com Rojo (2008) cerca de $20 \%$ eram textos de divulgação científica.

Já no ensaio produzido em 2008, Rojo discute práticas e eventos de letramento, típicos da escola, que colocam em circulação gêneros da divulgação científica. Rojo (2008) enfatiza que esse 
gênero integra intermitentemente as práticas/eventos de letramento escolares, embora raramente sejam abordados como objetos de estudo. Frequentemente são usados como ferramentas para o ensino de outros conteúdos. Nesse ensaio, ela indica alguns mecanismos do processo de apropriação que ocorrem nos eventos de letramento de sala de aula envolvendo textos de divulgação científica. A partir das análises de cenas de sala de aula, concluiu que predomina, na interação dos alunos com o discurso de divulgação científica, um estilo autoritário - que varia do texto de cor ao texto revozeado-, em detrimento do estilo internamente persuasivo em que a voz do aluno se hibridiza ao discurso de origem, permitindo ecoar suas apreciações de valor.

A propósito Cunha e Giordan (2009) alertam para o fato de que propostas de inclusão de textos de divulgação científica na sala de aula devem levar em conta, sobretudo, o contexto em que estes textos circulam. Pois a mudança de uma esfera para outra exige trabalho de análise crítica e discussão. Para esses autores, a mudança de esfera implica, obrigatoriamente, mudança dos seus significados e de sua compreensão. Para eles, garantir que um texto de divulgação científica seja mais agradável que um texto do livro didático não garante a compreensão da Ciência, nem tão pouco dos termos expressos no texto de divulgação (CUNHA \& GIORDAN, 2009).

Tendo em vista a importância do gênero de divulgação científica para a aprendizagem das crianças, este trabalho tem como propósito investigar o uso e a apropriação da revista Ciência Hoje das Crianças (CHC) em uma sala de aula em que a revista foi utilizada. Nossa proposta é apresentar uma reflexão do processo vivido pela turma em interação com a revista $\mathrm{CHC}$, por meio de uma narrativa e análise de dois episódios que lançou mão de uma descrição cuidadosa das interações comunicativas. Considerando a importância da revista $\mathrm{CHC}$ para o desenvolvimento desta investigação, segue uma breve apresentação do periódico, para em seguida, tratarmos de questões metodológicas, dos resultados que foram organizados em cenas ocorridas na sala de aula.

\section{A REVISTA CIENNCIA HOJE DAS CRIANÇAS}

Criada em 1986, Ciência Hoje das Crianças (CHC) é a revista de divulgação científica para crianças da Sociedade Brasileira para o Progresso da Ciência - SBPC. A revista tem caráter multidisciplinar e publica, sob as formas mais variadas, temas relativos às ciências humanas, exatas, biológicas, às geociências, ao meio ambiente, à saúde, às tecnologias e à cultura. Seu objetivo é promover a aproximação entre cientistas, pesquisadores e público infantil em geral, destacando 
práticas e conhecimentos científicos e estimulando a curiosidade das crianças para fatos e métodos das ciências. Além disso, ela se propõe a divulgar aspectos da cultura brasileira, possibilitando a ampliação do universo cultural das crianças.

A CHC tem como público-alvo crianças entre 7 e 14 anos. A publicação recebe tratamento gráfico e editorial cuidadoso e diversificado, que lhe confere uma de suas principais características: a agilidade de linguagem escrita e visual. Os artigos científicos são enviados espontaneamente ou encomendados pela equipe. Os artigos da $\mathrm{CHC}$ recebem tratamento jornalístico, mas sempre são assinados por pesquisadores, fonte daquela informação.

A CHC surgiu como encarte da revista Ciência Hoje dos adultos e, ao longo de sua história, a CHC foi penetrando nas escolas, adquirindo caráter paradidático, não proposto inicialmente. Até o ano de 2011, mais de 60 mil escolas públicas do Brasil recebiama revista em suas bibliotecas. Nos anos anteriores a essa data a revista tinha uma tiragem de 340 mil exemplares por mês. Dessa parcela apenas 10\% eram assinantes. Em uma palestra proferida na Universidade Federal de Ouro Preto, no dia 21 de junho de 2011, Bianca Encarnação, Editora Executiva da CHC, ressaltou que o conteúdo da revista sofre influência dos Parâmetros Curriculares Nacionais e por essa razão é comprada pelo Ministério da Educação. Quanto à leitura da CHC, no ambiente escolar, Bianca Encarnação salientou sua preocupação sobre o acesso pelas crianças de escolas públicas. A editora considera importante o papel do professor em garantir o acesso das crianças à revista e aos textos de divulgação científica em geral para democratizar a ciência. Foi compartilhando com posições como essa que investimos em pesquisas sobre a divulgação científica para crianças (ALMEIDA, 2001; ALMEIDA e GIORDAN, 2014) e encontramos, nesse percurso um campo de estudos, ainda pouco explorado, que reafirma a importância desse material para o desenvolvimento do letramento nas aulas de ciências nos anos iniciais do ensino fundamental.

\section{METODOLOGIA}

Para Smolka (2000, p. 28), a apropriação é a incorporação das práticas de uma dada cultura, no domínio dos modos de agir, pensar e se relacionar em um determinado contexto. Nessa perspectiva é no contexto de uma sala de aula, em uma escola da rede municipal de Belo Horizonte, que buscamos compreender os modos de uso e apropriação da revista Ciência Hoje das Crianças. 
Nesse lugar, investigamos a interação da professora e das crianças com a revista, como o espaço escolar transforma a leitura da $\mathrm{CHC}$ e é por ela transformado. Na sala de aula onde a pesquisa foi realizada, ascrianças se encontravam na faixa etária entre nove e dez anos $-4^{\circ}$ ano do Ensino Fundamental. A professora atuava nas séries iniciais por vinte anos e havia se formado em Pedagogia, fazia menos de dez anos. Ela e todos os responsáveis pelas crianças assinaram termo de consentimento livre e esclarecido para participar da pesquisa, no qual foram descritos os procedimentos de registro e a não identificação dos sujeitos de pesquisa quando da publicação dos resultados.

No que concerne ao trabalho com os eventos de sala de aula, optou-se pela análise microgenética (GÓES, 2000) dada a sua vinculação com a matriz sociocultural, resultando num relato minucioso dos acontecimentos. Para tanto, filmamos as aulas de Ciências, em uma das turmas que a professora atuava, durante três meses. O acervo da pesquisa corresponde a 18 horas de filmagens ordenadas por data, um caderno de campo, entrevistas de áudio gravadas e transcritas e documentos normativos da escola. Após cada filmagem, seguiam-se os seguintes procedimentos: assistir às fitas repetidas vezes, com o objetivo de representar as interações das crianças e professora com a CHC, os padrões discursivos das aulas e a organização do trabalho com a revista. Após esse minucioso exame das aulas, procedeu-se à construção de mapas de ações, que dimensionam em uma tabela as ações mediadas pelo discurso dos participantes, as formas de uso e apropriação da revista, o tempo transcorrido e as observações de campo (ALMEIDA, 2011).

Após a coleta dos dados e a construção dos mapas de ações, a narrativa foi utilizada como "memória pedagógica" (CUNHA, 1997) dos acontecimentos da sala de aula. Pois, de acordo com Cunha (1997), o trato dos dados narrativos tem como objetivo suscitar o reconhecimento e a reflexão do processo vivido. A propósito, assinala Ginzburg: "se a realidade é opaca, existem zonas privilegiadas - sinais, indícios que permitem decifrá-la” (GINZBURG, 1991, p. 177). Assim, emerge na narrativa algumas lembranças, imagens, pistas invisíveis, cenas do trabalho com o periódico. Essas cenas revelam: os objetivos da leitura da revista nas aulas de Ciências, como a revista é incorporada ao cenário das aulas, as interações e práticas de letramento mediadas pelo periódico, a apropriação de marcas do discurso de artigos da revista pelas crianças, as aproximações e afastamentos do trabalho com a revista na tradição escolar. A narrativa restitui a experiência com a revista na sala de aula enquanto as análises de dois episódios 
se justificam por considerarmos que neles ocorrem eventos-chave que apontam para indícios do uso e apropriação de uma revista de divulgação científica para crianças na sala de aula.

Por fim, é importante destacar que a metodologia escolhida para este estudo tem, como pressuposto subjacente, a tese fundamental de Vygotsky e Bakhtin segundo a qual os sujeitos aprendem na interação com o outro, mediados pela linguagem. São essas interações que devem ser investigadas ao se examinar o curso de ação do sujeito. Nessa perspectiva, para compreender os usos e a apropriação da revista $\mathrm{CHC}$, em sala de aula, foi fundamental o acompanhamento minucioso das interações de crianças e professora com essa revista, detalhando ações e relações interpessoais, focalizando como foram construídos os sentidos e significados em torno da $\mathrm{CHC}$ no processo de ensino.As cenas de sala de aula descritas a seguir mostram esse percurso.

\section{CENA 1}

As paredes cuidadosamente pintadas e enfeitadas foram o limite da primeira aula com a revista Ciência Hoje das Crianças. Nas estantes espalhadas pelos cantos da sala, estavam cadernos, livros didáticos e de literatura. A manhã estava quente. Pouco antes das 7 horas da manhã, nada se mexia. Alguns minutos depois, o barulho dos alunos ao entrar na sala parecia acordar toda a escola. Era o começo de mais uma aula de Ciências. O fim do turbilhão de vozes foi marcado pelo bom dia da professora que iniciou o trabalho ajeitando as crianças nas carteiras enfileiradas no espaço da sala. Terminada essa tarefa, ela colocou-se diante da turma e apresentou a pesquisadora como alguém que iria ajudar no trabalho de sala de aula. Após, caminhou até a sua mesa, recolheu uma pilha de folhas e explicou que naquele momento fariam um questionário sobre um material com o qual trabalhariam nas aulas de Ciências. As recomendações da professora foram expressas: o cabeçalho seria preenchido primeiro para evitar esquecimentos e, para responder às perguntas, seria necessário observar a imagem na folha com atenção. O exercício deveria ser realizado individualmente. Depois, escreveu a data no quadro e distribuiu os questionários. Não houve nenhuma manifestação de recusa ou queixume para a realização da tarefa. As crianças correram os olhos no papel e se colocaram a postos para a realização da atividade. Enquanto preenchiam o cabeçalho, alguns alunos murmuravam assuntos diversos. Uma aluna, em alto e bom som, quis saber se as perguntas poderiam se referir a qualquer revista CHC. O questionamento dessa aluna indicou que ela conhecia o 
periódico enquanto o sorriso e o aceno afirmativo da professora denunciavam a resposta de uma das questões para os mais atentos.

Aos poucos, o silêncio reinou na sala. Enquanto as crianças liam e escreviam, a professora caminhava entre as carteiras observando os registros, avaliando as respostas e corrigindo a postura dos alunos. Em alguns momentos, interrompia a caminhada atendendo à solicitação de crianças que pediam esclarecimentos de uma questão ou aprovação a uma resposta dada. Atenta ao relógio, a professora cronometrava o tempo das crianças, orientando para que respondessem à questão seguinte. Atendendo à solicitação de algumas crianças, a professora registrou várias palavras no quadro para auxiliar na escrita das respostas.

O fim dessa tarefa foi marcado pelo fim do silêncio. Então, a professora recolheu todos os questionários, colocou-se à frente da turma e anunciou a correção. Ela lia, comentava e avaliava as respostas. Assim, ensinava aos alunos a forma correta de elaborar respostas ao mesmo tempo em que apresentava a $\mathrm{CHC}$ às crianças e introduzia esse periódico na agenda da sala de aula. As crianças respondiam às questões como sendo uma tarefa rotineira.

Pouco depois da correção, a professora preparou o retroprojetor para que todas as crianças pudessem ver a capa de uma $\mathrm{CHC}$ na parede. A projeção causou um turbilhão de comentários. A professora perguntou às crianças o nome da revista, a data, os títulos, o que iriam encontrar naquela edição e o que a imagem representava. Encerrou esse momento com um discurso sério chamando a atenção para a importância da revista, que trazia temas de ciências e era produzida especialmente para crianças. Com a mesma postura buscou na mesa uma revista, abriu em uma página previamente marcada e leu: Por que soltamos pum? A leitura desse título quebrou a solenidade do momento e arrancou gargalhadas de toda a turma. Leu esse artigo rodeada por olhos e ouvidos atentos. Em alguns momentos, ela interrompia a leitura para esclarecer algumas palavras do texto. Depois, discursou mais uma vez sobre a importância daquele material que tinha como finalidade explicar alguns fenômenos da ciência para as crianças.

Enquanto a professora distribuía diferentes edições da revista para levarem para casa, muitos disputaram o número que continha o texto lido. Várias crianças esperaram em pé, ou saíram de seus lugares para escolher o periódico que desejavam ler. Ao receber as revistas, os alunos ficaram com olhos fixos nas imagens, folhearam, leram títulos, mostraram aos colegas, trocaram edições. As páginas da revista abriam às crianças um mundo até então desconhecido. Durante um tempo, cada qual do seu jeito explorou a revista. Passados alguns minutos, a 
professora deu prosseguimento à aula, registrando no quadro de giz definições de palavras e expressões como: manchete, editor, editorial, artigo, siglas, SBPC, divulgação científica, etc. Durante a cópia, várias crianças mantiveram abertas as revistas no colo ou sobre a mesa. E, entre uma cópia e outra, elas liam o periódico num gesto furtivo. Ao término da aula, a professora realizou a chamada e o sinal indicou a saída alvoroçada das crianças para o recreio.

\section{CENA 2}

$\mathrm{Na}$ manhã do segundo dia de trabalho com as revistas, a aula de Ciências era a última do horário. Ao entrar na sala, a professora cumprimentou as crianças com afeição e ocupou o mesmo lugar, à frente da turma, para falar aos alunos. Depois de chamar a atenção para o tempo curto da aula quis saber das crianças sobre a experiência de leitura da revista no ambiente doméstico. Foram muitas as crianças que queriam partilhar suas leituras. Depois de ouvir alguns alunos, a professora indicou um menino que manifestou o desejo de falar. Em silêncio, com uma postura corporal ereta, algumas crianças buscaram a voz e o olhar do relator. Iniciou-se, então, a sequência abaixo:

QUADRO 1. Episódio 2 - Relatos de leitura

\begin{tabular}{|c|c|c|c|}
\hline $\mathbf{T}$ & Participantes & Discurso & Comentários \\
\hline 1 & Professora & Felipe & $\begin{array}{l}\text { Aponta para um } \\
\text { aluno }\end{array}$ \\
\hline 2 & Felipe & $\begin{array}{l}\text { eu li } 0 \text { texto e o título é a linguagem dos códigos (...) } \\
0 \text { código é uma substituição de palavras por signos } \\
\text { (...) } 0 \text { código começou (...) é uma substituição de } \\
\text { palavras por signos o código começou quando um rei } \\
\text { (...) ele queria esconder um tesouro, aí ele trocou } 0 \\
\text { mapa por uns códigos porque se alguém achasse } 0 \\
\text { mapa ninguém ia entender (...) daí surgiu os códigos }\end{array}$ & \\
\hline & & $\begin{array}{l}\text { (...) depois, depois que eu lembro veio o código morse } \\
\text { que era os códigos que (...) com as mãos }\end{array}$ & $\begin{array}{l}\text { Movimento } \\
\text { com os }\end{array}$ \\
\hline 3 & Professora & $\begin{array}{l}\text { muito bem, tá vendo? a pessoa tem uma máquina que } \\
\text { faz um barulhinho, cada barulhinho corresponde a uma } \\
\text { letra (...) porque aí a pessoa de muito longe consegue } \\
\text { escrever uma mensagem, ela consegue pelo número } \\
\text { de toques, de barulhinho (...) uma outra pessoa que } \\
\text { já está treinada em ler esses códigos consegue ler os } \\
\text { sinais (...) pelo toque ele vai saber qual letra, né? mais } \\
\text { alguém gostaria de falar? }\end{array}$ & dedos no ar \\
\hline
\end{tabular}




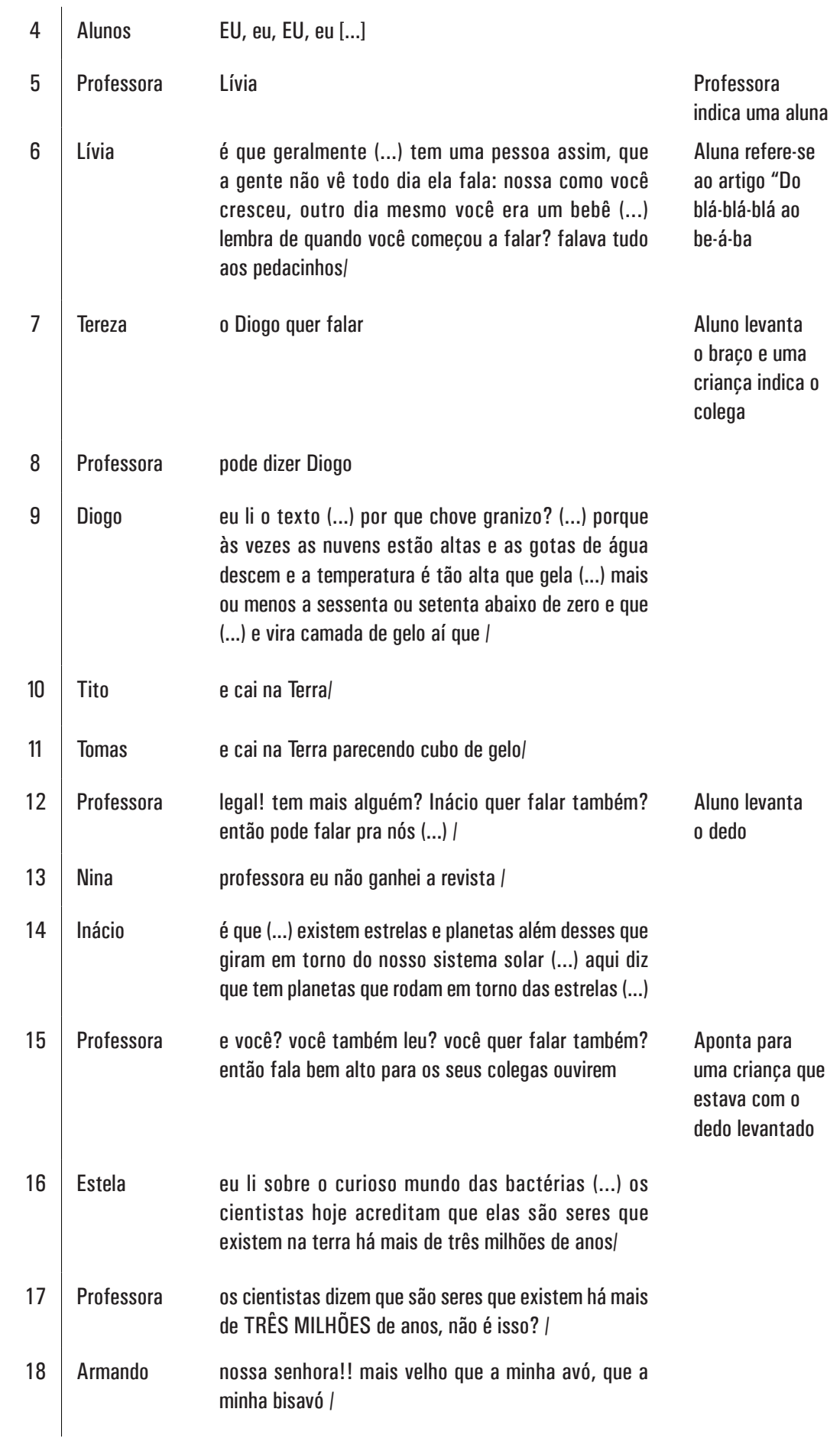




\begin{tabular}{|c|c|c|c|}
\hline 19 & Professora & e você acha que isso é ciência? & \\
\hline 20 & Helena & EU ACHO! & \\
\hline 21 & Professora & é ciência, né gente? agora o José (...) & \\
\hline 2 & José & $\begin{array}{l}\text { eu li com o meu primo essa aqui ó (...) } \\
\text { ele constrói sua própria casa com } \\
\text { pedras e flores e faz sua saliva como (...) / }\end{array}$ & $\begin{array}{l}\text { Aponta para } \\
0 \text { artigo }\end{array}$ \\
\hline & Sofia & cola (...) ele usa água da saliva e oxigênio & \\
\hline & Alunos & {$[\ldots] \mid$} & Incompreensíve \\
\hline
\end{tabular}

Depois de receber autorização para falar, um aluno, no turno 2, conta a sua experiência de leitura sobre o código Morse. Ele apresenta formalmente o texto destacando, em primeiro lugar, o título do artigo lido como uma estratégia que envolve a compreensão de como se deve anunciar um texto informativo e iniciar a apresentação na sala de aula. Em seguida, ele se concentra na explicação do que seria o código Morse e na história da invenção dos códigos. O dizer: que eu lembro, permite indiciar uma percepção em torno do nível de informatividade do texto, especialmente em relação à falta, à informação ausente - um fator que se concretiza, de modo mais claro, para a criança, durante o processo de apropriação do texto. $\mathrm{O}$ aluno tem consciência que outras informações existem no texto e não são ditas por ele.

Nessa exposição, percebe-se alto grau de coerência e coesão do discurso oral. A compreensão e a organização desse discurso não deixam a desejar com relação ao texto escrito. O texto escrito foi transformado para ser compreendido pelos ouvintes. Isso era regulado pela atitude de aprovação estampada no rosto das crianças. Afinal, o relator é aquele que fala para outro, que é, ao mesmo tempo, semelhante e distinto de si. Assim, no caso em questão, a fala do aluno era regulada pela compreensão que tinha do texto, mas instanciada pelo outro, a quem a fala era endereçada.

Ainda no turno 2 o aluno, ao mesmo tempo em que cita o discurso do outro: o texto que en li, se assume como sujeito de seu discurso misturando formalidade e aproximação com o discurso cotidiano. $\mathrm{O}$ texto oral não registra a totalidade do texto escrito o que envolve atividades de resumo, devendo a criança extrair aspectos essenciais do texto de divulgação científica. Percebe-se, também, no discurso desse aluno um apagamento do sujeito, gerando um discurso indireto e, ao mesmo tempo, uma costura narrativa, presente no texto 
escrito e no oral envolvendo o leitor e o ouvinte. A retextualização indica, além da compreensão do texto lido, organização do discurso em conformidade com as convenções do artigo e da oralidade que explicitam a informação em ambas as formas.

No turno 3, o feedback da professora é avaliativo com a função de confirmar a resposta e de redimensionar o discurso, realizando uma síntese. Desse modo, ela propicia a construção de conhecimento que possa ser compartilhado no grupo. Esse tipo de atitude docente foi constatado também por Edwards e Mercer (1988) em suas pesquisas sobre as interações na sala de aula. De acordo com esses autores, o professor faz comentários metacognitivos e metadiscursivos quando acredita que algum aluno possa ter dificuldades de compreensão do que está sendo discutido.

Para Bakhtin (1997) compreender o universo da palavra não é tarefa simples. É preciso pensar em sua relação com outras palavras, no contexto em que a palavra é produzida e na relação que ela estabelece entre quem a produz e o interlocutor. Assim, ao incentivar as crianças a falarem sobre os textos da revista a professora evidencia a linguagem viva e dinâmica dos textos de divulgação científica e colabora para a produção de textos orais e para o reconhecimento de diferentes e/ou novos significados para as palavras. Logo, a professora atua diretamente na apropriação do significado das palavras junto de seus alunos. Ao assim proceder, ela destaca o lugar privilegiado que a linguagem oral ocupa para observação da interação. E, segundo Bakhtin (1997), a linguagem somente é concebida, concretizada, entre indivíduos socialmente organizados. É na relação entre os indivíduos que o significado se constitui.

Assim, no turno 3, e ao longo de toda a sequência, a professora convida as crianças a falarem, estabelecendo com eles um processo de interlocução. Mas, nesse processo, elas aparecem como protagonistas do evento e não apenas como meras espectadoras. O convite da professora tem o caráter mais de persuasão do que de imposição.

Já o turno 4 caracteriza-se pelo entusiasmo das crianças pelo desejo de falar do texto lido. E os turnos 6, 9 e 22 caracterizam-se pelo comprometimento na compreensão do artigo. A retextualização, nesses turnos, reduz tão exageradamente as informações que é difícil ao ouvinte entender o discurso. Ora, se o traço principal do gênero de divulgação científica é a informação, é necessário que nos discursos orais ela apareça nítida. No entanto, o que se vê, nesses turnos, é um apagamento da informação acarretando comprometimento na compreensão do texto. 
No turno 9, um aluno apresenta o texto que explica a chuva de granizo e outras crianças o auxiliam na explicação. É deste esforço de encontrar sentidos na palavra do outro que decorre a compreensão. A compreensão não é uma atitude passiva de entendimento da fala do outro. Afirma Vygotsky: "Para compreender a fala de outrem não basta entender suas palavras - temos que compreender o seu pensamento". (VYGOTSKY, 1999, p.130). A compreensão se dá no confronto dos sentidos que só se realiza no processo de formação de uma réplica, de uma atitude ativa e responsiva.

No turno 13, uma aluna reclama a falta da revista. Esse é um indício importante do valor que a $\mathrm{CHC}$ passou a ter para as crianças. Aliás, durante a pesquisa de campo nunca reclamaram da falta dos textos fotocopiados que não receberam, mas no caso das revistas todos cobravam da professora o número que não receberam quando faltavam à aula.

No turno 16, uma aluna também anuncia o texto com o título e, além disso, recorre à voz dos cientistas para a construção da sua fala. O cientista aparece como "o autor" - são eles que dizem, eles acreditam... Ainda assim, essa criança assume a autoria do texto, pois a criança fala referindo-se aos cientistas e, "saber trabalhar a língua situando-se fora da língua, é aquele que possui o dom do dizer indireto" (BAKHTIN, 1997, p. 337). Dessa maneira, na construção desse discurso indireto as crianças iam se tornando autoras do seu próprio discurso. Ao retextualizar elas assumiam a autoria. Esse trabalho de compreensão dos artigos denota, também, a diferença de investimento que a criança faz entre uma narrativa do vivido e a retextualização de texto informativo. No relato do texto informativo, o vivido é evitado, deslocando a ênfase para a voz de autoridade do texto - o cientista - o outro que fala.

No entanto, no turno 18, esse vivido aparece em uma situação que mostra a importância da relação dialógica no trabalho com a leitura nas aulas de Ciências. A criança compara o tempo de vida das bactérias na Terra ao tempo das avós. Ainda que a dimensão do tempo seja difícil para a compreensão desse aluno, ao ouvir a informação ele compara e internaliza as ideias e, nesse processo, vai elaborando uma forma de diálogo do vivido com as questões relativas à ciência do texto oral e escrito.

No turno 21 a professora legitima o discurso da revista ao ressaltar que as informações apresentadas pertencem ao campo das ciências.

De modo geral, no decorrer desse episódio, os conhecimentos são partilhados por crianças que leram o mesmo artigo. Isso pode ser observado, por exemplo, no turno 23, quando uma aluna auxilia o colega na explicação do artigo. Esse fator é considerado de grande 
relevância para esta investigação uma vez que, nessa dinâmica discursiva, ficam explicitados os movimentos e recursos constitutivos do processo de construção coletiva do conhecimento na sala de aula. Nesse sentido, constata-se a importância do outro no processo de apropriação de um conhecimento. Nessa situação, percebe-se a reflexão do outro, que também pensa no texto, constrói sentidos e está atento ao discurso. Nesse processo, as crianças reelaboram a informação e produzem conhecimentos e não apenas transmitem as ideias do artigo, mas também alteram, de maneira significativa, as relações de ensino na sala de aula.

Ainda nessa aula, em outra sequência - turno 25 a 37 - as crianças prosseguem com os relatos dos artigos lidos, mas nesta sequência aparece em alguns turnos de fala um discurso narrativo, menos pragmático que a primeira. Os textos das crianças são mais persuasivos de maneira que a explicação presente em cada artigo da revista $\mathrm{CHC}$ aparece na oralidade de maneira convincente, como uma extensão do discurso canônico. Vejamos então, a $2^{\mathrm{a}}$ sequência:

QUADRO 2. Episódio 2 - Relatos de leitura

\begin{tabular}{|c|c|c|c|}
\hline $\mathbf{T}$ & Participantes & Discurso & Comentários \\
\hline 25 & Professora & $\begin{array}{l}\text { vamos ouvir a Lourdes... ela quer fazer um comentário } \\
\text { sobre } 0 \text { que ela leu }\end{array}$ & \\
\hline 26 & Lourdes & $\begin{array}{l}\text { é (...) eu li que uma pesca lá dos golfinhos com os } \\
\text { seres humanos (...) que os golfinhos (...) eles ajudam } \\
\text { os pescadores a pescar porque quando eles (...) é (...) } \\
\text { os golfinhos estão (...) acho que na beira da maré da } \\
\text { praia eles encurralam os peixes e os pescadores e } \\
\text { jogam é (...) coisinhas lá neles } ~\end{array}$ & $\begin{array}{l}\text { Estudantes voltam } \\
\text { a atenção para a } \\
\text { aluna e ficam em } \\
\text { silêncio }\end{array}$ \\
\hline 27 & Catarina & a rede I & \\
\hline 28 & Lourdes & $\begin{array}{l}\text { é (...) a rede e pescam os peixes e (...) e (...) eles (...) } \\
\text { os golfinhos (...) eles também gostam (...) eles são } \\
\text { muito brincalhões porque eles não têm medo de seres } \\
\text { humanos, né? eles gostam de brincar nas ondas, } \\
\text { gostam de brincar (...) sabe umas plantas que ficam } \\
\text { flutuando assim? । }\end{array}$ & $\begin{array}{l}\text { Faz gesto de onda } \\
\text { com a mão }\end{array}$ \\
\hline 29 & Professora & sei $/$ & \\
\hline 30 & Fátima & algas marinhas / & \\
\hline
\end{tabular}




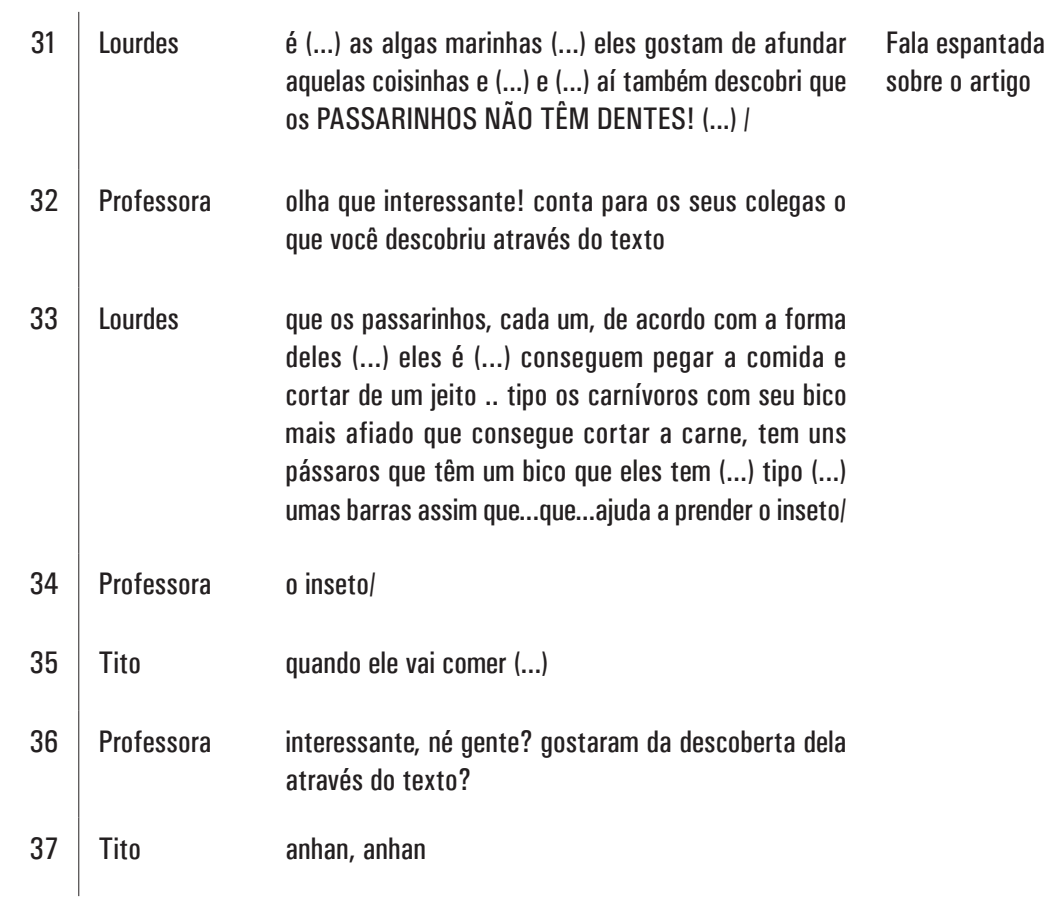

No turno 26, observa-se que a aluna inicia seu discurso com a expressão eu li. A aluna faz referência ao artigo, nesse caso, é flagrante a preocupação em indicar o discurso do outro. Depois, o discurso aparece em $3^{\text {a }}$ pessoa revelando um apagamento do autor. Também na linha 1, ela usa a palavra golfinho apesar do animal ser denominado, em quase totalidade do texto da revista como boto. Segundo Vygotsky (1991, p. 50) são as experiências cotidianas da criança com o uso da palavra que leva à generalização. No turno 28 , a aluna inicia seu discurso com muitas hesitações, uma marca da linguagem oral.

No turno 31 a criança altera o tom de voz ao informar, impressionada, que os pássaros não têm dentes. Essa explosão vocal é a dimensão emotiva do texto oral que não aparece no discurso escrito. A informação envolve tanto a aluna que vem acompanhada de movimentos corporais que ajudam a significar as palavras no processo de interação verbal. $\mathrm{O}$ artigo, para a criança, é muito curioso e o envolvimento dela no conteúdo do texto é tão forte que ela ri, gesticula, balança o corpo e altera o tom de voz. Dessa forma, os outros ouvintes ficaram entusiasmados pelo artigo e presos na fala dessa aluna. A voz, dessa forma, acompanha e apoia a organização e complementação de sentidos constitutivos do discurso. Sendo assim, os recursos do discurso oral ultrapassam a dinâmica do universo do sistema linguístico. 
A análise desses fragmentos mostra que as crianças deixam transparecer nas formas de falar suas experiências com a revista CHC. As exposições orais das crianças parecem constituir-se como monólogos. As vozes que compõem os textos das crianças se ocultam sob a aparência de uma única voz. Contudo, de acordo com Bakhtin (1992), qualquer discurso é permeado por palavras de outrem, essas vozes podem ser assimiladas, citadas ou refutadas de forma explícita, ou podem ser disfarçadas sob o aspecto de um discurso monológico, como acontece nos relatos das crianças.

Em geral, não há perguntas nem longos comentários após os relatos. Contudo, percebe-se a atitude compreensiva e responsiva daquele que leu o mesmo texto e daquele que ficou na escuta. Os relatores interagem com a plateia por meio de expressões como: eu li sobre, depois, que eu lembro, a gente, aqui diz, é que dão significação ao texto por um viés envolvente. Ao manter o silêncio e apresentar disposição para ouvir, apreciar os textos dos colegas, acrescentar e concordar, a turma desempenha um papel importante na organização discursiva da exposição como também observa Bovet (1999, p. 70 apud ROJO).

Outro aspecto observado nessa sequência é a passagem do texto escrito para o texto oral denominada por Marcuschi de retextualização (2001, p. 48). Nesse processo, as crianças construíram uma espécie de revisão da própria fala. Desse modo, a retextualização tem como princípio o dialogismo como constitutivo da linguagem, pois na retextualização é a voz alheia que perpassa inevitavelmente o discurso do falante. Assim, no turno 33, o discurso de uma aluna revela que o conceito expresso no texto vai sendo ampliado, reconstruído, englobando ideias cada vez mais sofisticadas acerca do assunto. A princípio, ela cita, de maneira generalizada os passarinhos que, de acordo com a forma deles conseguem pegar a comida. Mais adiante, cita os pássaros que, "com seu bico afiado conseguem cortar a carne". Esse processo de retificação e de retomada das ideias é fundamental no texto oral e escrito. É constituinte do ato de revisar. Esse movimento de avanços e recuos assinala a possibilidade de o aprendiz lidar com o texto de sua autoria. Essa construção é um movimento de um sujeito que é capaz de pensar, com autonomia, a leitura que faz do texto, porque está se apropriando de mecanismos que permitem a (re)construção de um texto a partir da interação com ele.

Depois dessa sequência, as crianças foram orientadas a realizar a leitura individual e silenciosa que foi invadida por comentários de alunos e da própria professora sobre o que encontraram na $\mathrm{CHC}$. Nesse entremeio, algumas crianças esqueceram o corpo cruzando as pernas sobre a cadeira, ou esparramando-se sobre a mesa. Dessa forma, a 
revista se dava a ler, se mostrava, se insinuava com os corpos visíveis. Em algumas ocasiões, a professora corrigia essa postura, em outras, verificava o texto que deixava as crianças tão relaxadas. $\mathrm{O}$ sinal anunciou o fim do horário de aula enquanto a professora incentivava a leitura em casa e anunciava a continuidade do trabalho com a $\mathrm{CHC}$ para a aula seguinte.

\section{CENA 3}

Depois de cumprir os rituais de início da aula, a professora apresentou o assunto do dia como um problema a ser resolvido coletivamente: "em uma de nossas aulas surgiu uma questão que não conseguimos responder. Então, hoje vamos trabalhar essa dúvida: por que a girafa tem opescoco comprido?' Enquanto as crianças colocavam sobre as mesas os cadernos e revistas $\mathrm{CHC}$, a professora escreveu no quadro de giz a pergunta convidando-as a manifestar suas opiniões. A pergunta atingiu em cheio os alunos. Em poucos minutos, vieram à tona vários comentários. Em meio a esse alarde, ela ordenou que levantassem o dedo para falar e ouvissem uns aos outros. Todas as hipóteses das crianças foram registradas no quadro pela professora. Comentários sobre o tempo de gestação das girafas, a alimentação desses animais e a maneira como as girafas dormiam foram citados por uma criança que havia obtido essas informações no zoológico de Belo Horizonte. A dúvida sobre a entrada desse animal na arca de Noé, em virtude do tamanho dos pescoços, foi um assunto que também crepitou na aula. As crianças que não se manifestavam pareciam concentradas nessas colisões de informações e opiniões. Tendo escutado todas as manifestações, as crianças terem copiado as hipóteses sugeridas, a professora anunciou o início de um filme ${ }^{3}$ sobre o tamanho do pescoço das girafas. Era um filme conciso, produzido para crianças, que explicava, de forma mais geral, as teorias atualmente legitimadas sobre a evolução das espécies. No término da exibição do filme, uma menina aparentemente incomodada disse que identificou a sua explicação na voz de um cientista, mas não sabia dizer porque a sua explicação era diferente da apresentada. A professora então distribuiu o texto da CHC, que gerou todo o questionamento dessa aula e perguntou às crianças o que haviam identificado no filme e no texto. Os alunos citaram aspectos relacionados à imagem e à linguagem. Ela insistiu na pergunta esperando que percebessem as duas teorias. $\mathrm{Na}$ tentativa de explicar o conceito, as crianças serviram-se de palavras do artigo e do filme. Algumas crianças incorporaram às palavras delas, termos, expressões e sentidos que caminhavam em direção de uma 
explicação ligada à herança genética. Após as explicações das crianças sobre traços herdados dos pais, a professora sugeriu a produção de um texto justificando que serviria para auxiliar a memória da pesquisadora ali presente. As crianças fizeram a tarefa com muito entusiasmo. Escreveram sem reclamar, desenharam e, algumas até se atrasaram para o horário do recreio. Finalizada a produção de texto, a professora, de olho no relógio, distribuiu revistas às crianças. Enquanto alguns alunos liam, outros caprichavam no desenho. $\mathrm{O}$ sinal anunciou o fim da aula e algumas crianças ainda estavam colorindo seus desenhos.

\section{CENA 4}

Naquela tarde, ao chegarà sala de aula, a professora cumprimentou os alunos e, como de costume, organizou as carteiras enquanto aguardava a chegada das outras crianças. Depois de um tempo, distribuiu o texto fotocopiado da revista CHC: $O$ pão, o vinho, fungos em ação. As crianças foram orientadas fazer a leitura individual e silenciosa. Após a leitura do artigo, a professora perguntou aos alunos sobre a compreensão do texto como mostra o quadro:

QUADRO 3. Episódio 4 - 0 que vocês entenderam deste texto?

\begin{tabular}{|c|c|c|c|}
\hline $\mathbf{T}$ & Participantes & Discurso & Comentários \\
\hline 1 & Professora & $\begin{array}{l}\text { no momento em que o Henrique estava lendo, ele me } \\
\text { perguntou o que que é fungo? este texto vai informar } \\
0 \text { que que é e o que ele faz no pão e no vinho. E aí? } \\
\text { você conseguiu descobrir o que é fungo? }\end{array}$ & \\
\hline 2 & Inácio & & $\begin{array}{l}\text { Balança } \\
\text { a cabeça }\end{array}$ \\
\hline 3 & Clara & EU SEI!! & $\begin{array}{l}\text { Aluna levanta } \\
0 \text { dedo }\end{array}$ \\
\hline 4 & Professora & alguém consegue me dizer o que é?| & \\
\hline 5 & Clara & EU SEI!! & \\
\hline 6 & Alunos & é um ser microscópio [...] & Falam juntos \\
\hline 7 & Professora & $\begin{array}{l}\text { há! é isso aí (...) é um ser microscópio que a gente não } \\
\text { consegue ver (...) eu expliquei isso aqui (...) ver a olho nu/ }\end{array}$ & \\
\hline 8 & Armando & eu li essa parte aíl & \\
\hline
\end{tabular}




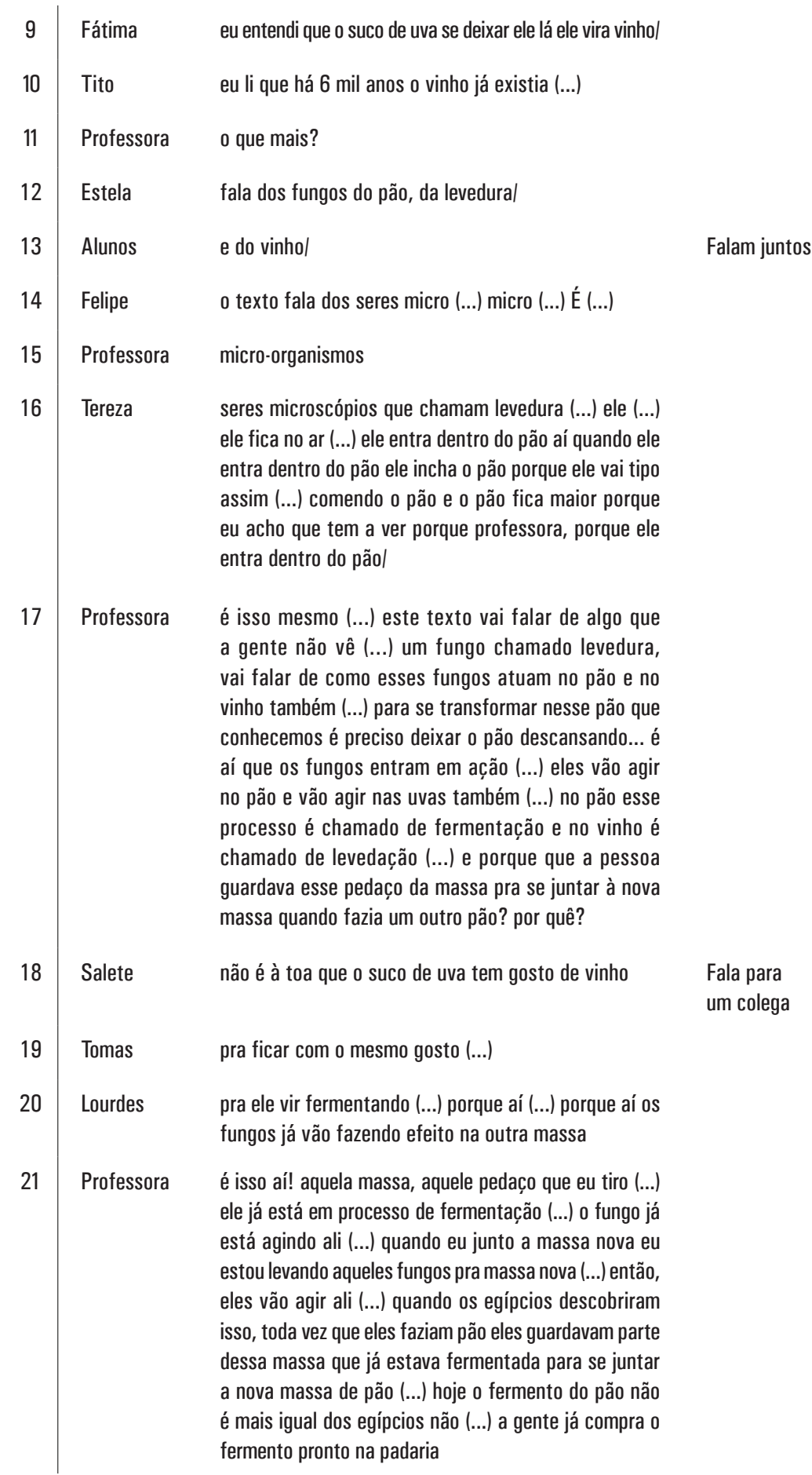


Esse episódio mostra a interação das crianças e da professora com o gênero de divulgação científica. No turno 1, ao perguntar sobre a compreensão do conceito de fungo ela indica para as crianças uma das características do texto que leram: um artigo que explica sobre o que é fungo e o que ele faz no pão e no vinho. A preocupação da professora em destacar o tipo de texto evidencia o propósito de ensinar a funcionalidade de um artigo que apresenta o conceito na aula de ciências. De certo modo, ao perguntar às crianças sobre a compreensão do texto, a professora permite que as crianças aprendam outro modo de falar sobre um conceito da ciência e que as ideias a respeito da experiência de leitura ganhem visibilidade e sejam veiculadas no grupo.

No turno 6, as crianças respondem prontamente identificando o fungo como um ser microscópico, o que não indica necessariamente compreensão desses conceitos que estão circulando em sala de aula. Essa significação, que aparece reiteradas vezes na enunciação - turnos 18, 26 e 28 -, é dada no artigo da CHC. Essa significação do fungo como um ser microscópico pode ser considerada o estágio inferior da capacidade de atribuir sentido, pois é a palavra cristalizada do dicionário, mas, não por isso menos necessária à atribuição de significado.

No turno 7, a professora endossa o significado dado pela criança e lembra que essa palavra já fora explicada na sala. Nos turnos 9 e 10, os alunos citam o vinho, mas não estabelecem relações com o processo do pão. Entre os turnos 12 e 14, algumas crianças revozeam o já dito.

No turno 16, além do uso das palavras microscópio e levedura, uma criança tenta explicar o processo de fermentação. Mais uma vez, as palavras de uso cotidiano são a ponte para a explicação e tentativa de entendimento. Vale ressaltar que essa criança, ao definir os fungos, se utiliza das mesmas palavras do texto.

$\mathrm{Na}$ tentativa de fazer com que todos compreendam a questão, a professora retoma-a e faz uma síntese de tudo já dito até aquele momento da sequência. Isso pode ser visto no turno 17. Como já constatado por Rojo (2004) em sua pesquisa, a professora utiliza como estratégia o revozeamento e um estilo de autoridade para levar as crianças à construção das ideias do texto. E nesse mesmo turno, ela faz uma pergunta tentando ir além com a construção do significado. Nos turnos 18, 19 e 20 as crianças comentam acerca da necessidade da presença dos fungos. No turno 21, mais uma vez, a professora sintetiza as ideias apresentadas e recorre ao texto sobre a história dos pães, para dialogar com o artigo. Até o turno 21 artigo a produção dos textos orais se baseia nas retextualizações do artigo pela professora e pelas crianças. 
E no turno 22, uma criança faz uma pergunta que não está presente no artigo: e quando põe pra assar os bichinhos lá morrem? Essa pergunta altera o discurso. É a palavra internamente persuasiva, à medida que seu processo de assimilação se dá no entrelace com as palavras da professora, do artigo e da criança. Conforme Bakhtin, a palavra internamente persuasiva se entrelaça de maneira estreita com a própria palavra; portanto, é "metade nossa, metade de outrem", pois "desperta nosso pensamento e nossa nova palavra autônoma, em que ela organiza do interior as massas de nossas palavras, em vez de permanecer numa situação de isolamento e imobilidade" (BAKHTIN, 1997). Dessa maneira, a pergunta realizada no turno 22 tem importância fundamental no desenvolvimento do conceito, porque é exatamente essa atitude responsiva, que desperta o motor da significação. Esse movimento discursivo da aluna reafirma sua compreensão ativa por ser mediada por uma pergunta autêntica que expõe suas necessidades e motivos, como registrado no quadro a seguir:

QUADRO 5. Episódio 4 - 0 que vocês entenderam deste texto?

\begin{tabular}{|c|c|c|c|}
\hline $\mathbf{T}$ & Participantes & Discurso & Comentários \\
\hline 22 & Pilar & e quando põe o pão pra assar os bichinhos lá morrem?| & \\
\hline 23 & Professora & quando o quê?| & \\
\hline 24 & Pilar & quando põe pra assar (...) & \\
\hline 25 & Professora & $\begin{array}{l}\text { quando você põe pra assar? acho que eles morrem, } \\
\text { né? porque senão eles continuariam crescendo, né? } \\
\text { quando você põe pra assar a temperatura está muito } \\
\text { alta (...) olha (...) o pão (...) ele não continua a crescer } \\
\text { depois de assado o que significa que os fungos não } \\
\text { estão em ação (...) por outro lado, se você deixar } 0 \\
\text { pão num lugar...vai acontecer outro processo com ele, } \\
\text { vai ter o fungo agindo nele (...) se você deixar o pão } \\
\text { em qualquer lugar sem cobrir, sem nada o que que vai } \\
\text { acontecer com ele? }\end{array}$ & \\
\hline 26 & Catarina & ele vai murchar/ & \\
\hline 27 & Professora & ele vai murchar e depois? & \\
\hline 28 & Nina & ele vai mofar/ & \\
\hline
\end{tabular}




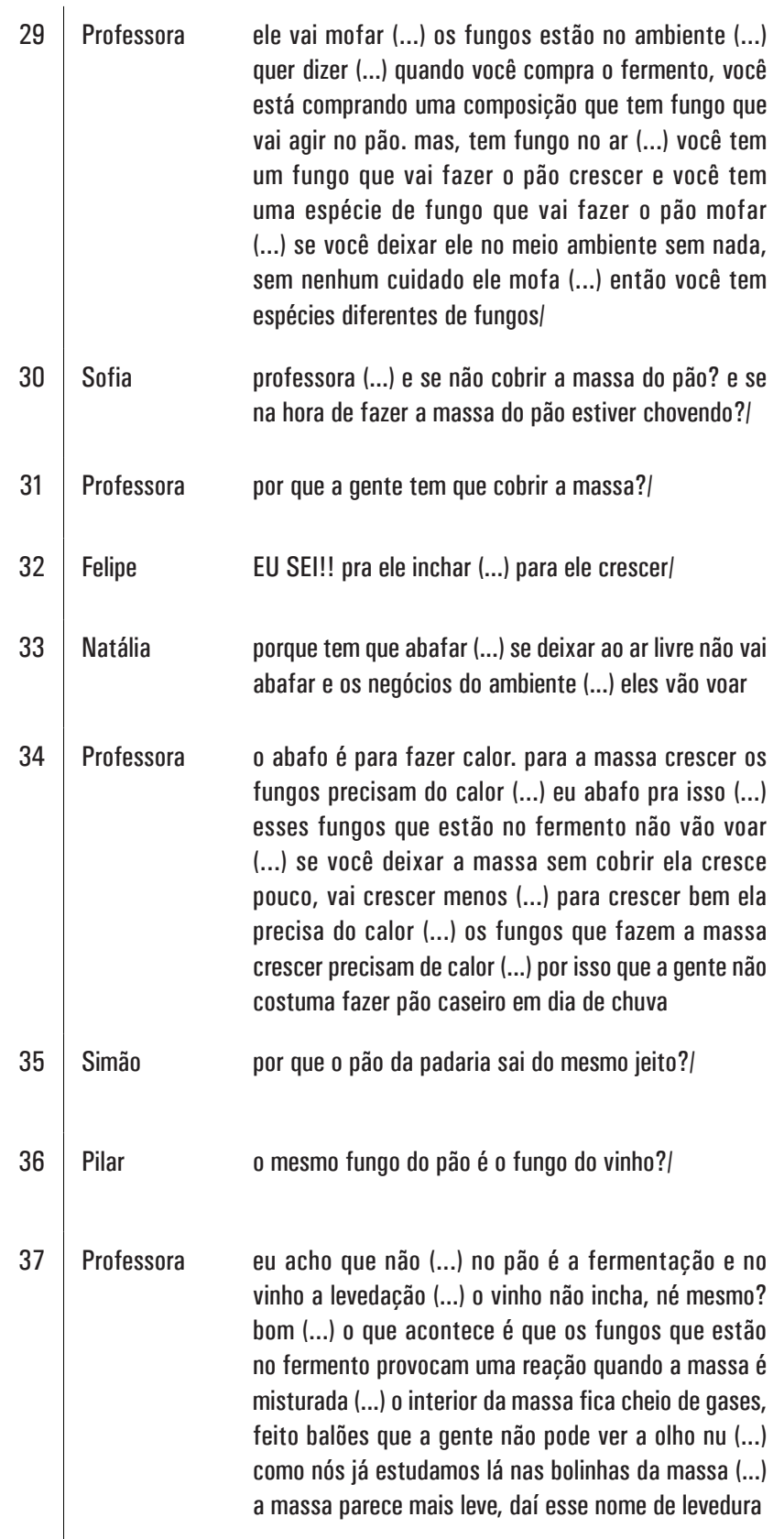

Refere-se

aos fungos

Fala baixo

E no turno 25, a professora dirige à criança com uma resposta igualmente original, que não está artigo. A professora impõe a sua voz, sem que seu discurso implique apagamento das vozes alheias, 
mas uma mistura de vozes cujas fronteiras que delimitam as palavras das crianças, do texto e da própria professora são tênues.

Em resposta ao enunciado da professora, que informa a ação dos fungos no ambiente, uma criança pergunta, no turno 30: se na hora de fazer a massa do pão estiver chovendo? e o que acontece se não cobrir a massa? Essas questões podem parecer, a princípio, fora de propósito porque não se limitam ao artigo. No entanto, as palavras de autoridade e internamente persuasivas não se excluem mutuamente, mas coexistem de forma tensa e conflituosa. É a explicação da professora da existência dos fungos no ambiente e a experiência cotidiana da criança ao fazer o pão que leva a elaboração dessa pergunta. E é amparado na experiência, livre de coerções, que um menino responde que a massa precisa ser coberta para inchar e crescer. Nessa mesma direção, outra aluna afirma, no turno 33, que a massa é coberta porque precisa ser abafada para que os fungos não voem. Esse turno apresenta, claramente, o conflito de vozes, pois as crianças, quando produziram o pão em uma aula anterior, elas abafaram a massa para que a ação dos fungos fosse intensificada pela manutenção da temperatura. No entanto, a ideia de que os negócios do ambiente podem voar com a massa descoberta é um ponto de tensão, associado à esfera cotidiana.

No turno 22, observa-se que a aluna denomina os fungos como bichinhos, e no turno 33, outra diz que são negócios do ambiente que voam. Afinal, essas denominações demonstram que as crianças estão realizando um trabalho de compreensão. Para as crianças, é difícil pensar nesses micro-organismos como não sendo outra coisa senão o que descrevem. Assim, se são seres vivos devem morrer, se são pequenos, são bichinhos e se estão no ambiente voam. Assim, essa multiplicidade de sentidos do conceito põe em cena essa tensão entre o discurso monológico e polifônico dos conceitos científicos. Esse percurso dos alunos na construção do conceito: fungos, bichinhos, negócios do ambiente revela uma linguagem que está sempre em evolução. À primeira vista, cada palavra anunciada pode parecer independente, mas carrega consigo ligações com inúmeras outras.

Assim, a partir do turno 22, reacende-se o dialogismo inerente à palavra. Como destaca Bakhtin, não se atinge "uma compreensão ativa de tudo quanto é outro e alheio se não formularmos a nós mesmos as nossas próprias perguntas" (BAKHTIN, 1997 p. 368). Por conseguinte, foi preciso que as crianças formulassem as suas próprias perguntas com base nas questões do artigo e da pergunta da professora para que pudessem avançar no processo de compreensão do conceito.

Em toda a sequência encontram-se no discurso da professora e das crianças, palavras do texto. Segundo Bakhtin (1992), parte das 
palavras pronunciadas provém de outrem. E a palavra do outro, levada a um novo contexto, evidencia o caráter dialógico da linguagem, à medida que ganha sempre novo significado, seja ele uma pequena mudança de tom, seja uma distorção - proposital ou não - do que foi dito.

Nessa sequência, a professora usa as palavras do artigo e explicita o objetivo do texto, com o claro propósito de ensinar sobre os fungos que agem no pão e no vinho. Ela faz uma intervenção, seguindo regras institucionalmente estabelecidas, com a autoridade que lhe compete, sintetizando as informações do texto na tentativa de as crianças compreenderem o conceito. Para Mortimer e Scott (2002), intervenções de autoridade são igualmente importantes e parte fundamental do ensino de Ciências. Pois, para esses autores, a linguagem social da ciência é essencialmente de autoridade.

Por fim, a professora chamou a atenção para os autores do texto. Uma aluna quis saber o motivo sobre os pães murcharem na sacola de plástico. Vários alunos opinaram sobre a questão e a professora encerrou o assunto explicando, de maneira direta, que dentro da sacola o pão suava e esse vapor preso umedecia-o. Ela distribuiu outras revistas $\mathrm{CHC}$ e um tempo foi dado para a leitura. Depois, as crianças copiaram a atividade para casa e aguardaram o início da outra aula.

\section{CENA 5}

Depois de recepcionar os alunos, a professora anunciou o início dos trabalhos com a distribuição de uma edição comemorativa da CHC sobre Charles Darwin e pediu que fizessem a leitura silenciosa e individual. Enquanto liam, a professora caminhava entre as carteiras observando os pequenos leitores, garantindo a ordem, mas os sussurros e olhares permeavam as leituras. As crianças liam assentadas, as carteiras eram enfileiradas e o tempo da leitura era cronometrado. Às vezes, a caminhada da professora era interrompida por uma criança que a interpelava para mostrar algum assunto de seu interesse. Ainda que a ordem fosse para ler apenas com os olhos, as crianças liam também com o tato e os ouvidos. Durante a leitura, ouviam-se os sons de quem se espantava com as imagens, de quem não acreditava no que lia, o silêncio de quem lia, com espanto, as entrelinhas, o gesto de quem se curvava para ver o que o colega lia. Apesar da orientação para a leitura silenciosa, ela não era solitária, privada. Mas, havia certo isolamento do mundo quando as crianças encontravam algo que muito lhes interessava na CHC. Transcorrido um tempo, a professora convidou as crianças a falar sobre a revista. Algumas 
estavam tão ávidas pela leitura que protestaram sobre o exíguo tempo da tarefa e continuaram absorvidas pela $\mathrm{CHC}$ enquanto a professora falava. Diante do convite para comentar aquela edição, uma aluna fez referência à leitura do artigo Mestres do disfarce sem fazer ligação com o assunto tratado na aula anterior. A professora lembrou-lhes que a revista tratava de um assunto estudado na aula anterior. Um menino reconheceu a figura de um cientista, mas não conseguiu lembrar-lhe o nome. $\mathrm{O}$ mesmo se deu com outras crianças que tropeçaram no nome de Charles Darwin. Esse menino quis saber da tradução daquele nome. A professora rapidamente levantou as sobrancelhas e explicou às crianças a não tradução de nomes próprios. Ela continuou ouvindo todos os comentários de crianças que adoravam pronunciar o nome de Darwin. Afinal, para elas, nos artigos da CHC, existiam palavras que não poderiam deixar de evocar. Uma menina duvidou que Darwin houvesse viajado pelo mundo todo e outra quis saber se ele ainda estava vivo. Um menino quis saber sobre quem estava correto: Darwin ou Lamarck? A professora rapidamente respondeu que, atualmente, a teoria de Darwin é mais aceita. A partir desse momento, ela ordenou que abrissem na página 2 e passou a trabalhar assuntos apresentados na revista, a partir da exploração do índice.

Depois de incentivar a leitura da revista em casa, foi até a mesa, pegou rapidamente três revistas e voltou a ocupar o seu lugar na sala. As crianças logo reconheceram na mão da professora a Recreio. Ela então mostrou as revistas tentando estabelecer uma comparação entre a CHC, a Recreio e a Super Interessante. Naquele momento as crianças não identificaram a $\mathrm{CHC}$ e a Super Interessante, como revistas de Ciências, como pensava a professora. A CHC e a Recreio eram para os alunos, simplesmente, revistas de criança. Essa classificação bastava ao entendimento sobre as diferenças entre esses materiais. Foi preciso a condução da professora para que as crianças fossem levadas a observar diferenças e semelhanças entre esses suportes.

Ao final da discussão, elas apontaram que a revista Recreio trazia como marca a distribuição de brinquedinhos e personagens da mídia na capa. Interromperam a professora para dizer que a qualidade do papel e as cores das imagens da Recreio eram diferentes, mais extravagantes que a CHC. Encerraram o assunto pontuando: "é que a Recreio tem mais brincadeira do que coisa para ensinar e Ciência Hoje para as crianças tem brincadeira que ensina e que informa para as crianças. E a própria capa fala CIÊNCIA”. Após, a professora escreveu no quadro um questionário para casa sobre localização e função de alguns elementos da revista como: preço, número, data, 
manchetes, editorial, artigos etc. Feito isso, a professora distribuiu um texto fotocopiado da $\mathrm{CHC}$ sobre a impressão de jornais e revistas. Antes de serem dispensadas para o recreio, elas leram silenciosamente esse artigo e, em seguida, a leitura oral, atendendo à ordem da professora que fez breves comentários sobre esse texto.

\section{CONSIDERAC̣̃̃ES FINAIS}

Em relação à questão geral deste trabalho, que busca compreender nas cenas de leitura da revista, o uso e a apropriação da revista $\mathrm{CHC}$ em sala de aula, constatou-se que as interações mediadas pela revista se dão no contexto de determinadas relações de ensino, contexto esse constituído e transformado por essas interações.

A interação entre professora e alunos no uso da revista concretizou-se, principalmente, de duas formas: mediante o diálogo com toda a turma evidenciando comentários e respostas de algum aluno, em particular, e por meio de atividades escolares tendo a vOz da professora presente no grupo, marcando e condicionando os processos de elaboração dos alunos. A maior parte dos trabalhos desenvolvidos em sala de aula estruturou-se em torno da leitura de textos fotocopiados da revista.

A CHC interferiu nas formas de organizar e administrar a aula assim como sofreu interferências na natureza do gênero produzido. Essa interferência não se deu propriamente na estrutura da aula - ler textos, conversar sobre eles, responder a questionários e corrigi-los mas nas formas que outros gêneros começaram a fazer parte do ato comunicativo modificando o gênero aula.

Ademais, as cenas de sala de aula revelam um predomínio de gêneros do domínio escolar, pois os gêneros que se manifestam na sala de aula obedecem às restrições normativas da instituição. Em se tratando da esfera escolar, segundo Bunzen e Rojo os gêneros que aí circulam estão ligados aos projetos discursivos realizados no enunciado. Uma das características essenciais desse projeto é a finalidade didática de ensinar, instruir (2005, p. 90). Dessa forma, os gêneros da CHC aparecem em sala de aula didatizados. No desenvolvimento do trabalho com a $\mathrm{CHC}$, dentre os gêneros escolares, percebem-se àqueles que são utilizados para organizar o ambiente de aprendizagem, como o questionário, as anotações de aula, os exercícios e o para casa.

No cotidiano da sala de aula, as práticas mediadas pela revista foram marcadas por um hibridismo de velhas e novas escolhas 
pedagógicas e foram acompanhadas por tensões. Um primeiro aspecto desse movimento de tensões é que o ensino a partir da revista, no contexto escolar, não é um processo espontâneo, ao contrário, ele é controlado e guiado pelos objetivos estabelecidos e pelo tempo escolar. Outra tensão evidenciada no uso da $\mathrm{CHC}$ em sala de aula está no "fechamento" do discurso que se pretende na aula e na "abertura" que o artigo propicia, que é uma das fontes da dialogia no movimento discursivo. Assim, se por um lado, a presença da revista evoca práticas já consolidadas na sala de aula, por outro, indicam tensões e conflitos que vão permitindo a emergência de novas práticas, outros espaços de interlocução e possibilidades do dizer da professora e das crianças nas relações que vão travando com a revista. Esse movimento de tensão também está na revista que apresenta uma ambiguidade de trazer, de um lado, a voz da ciência e de outro, fomentar a curiosidade das crianças trazendo outras vozes para a sala de aula. Nesse sentido, verificou-se que os textos de CHC promovem a dialogia e também a atitude responsiva das crianças, porque ao longo dos textos podemse encontrar perguntas, imagens, um texto aberto, mais temático, um texto narrativo que convida o leitor para entrar na "história".

Outro aspecto observado é que as crianças e a professora construíram uma relação cognitiva e afetiva com o material e demonstram um (re)conhecimento da CHC como um material em que a aprendizagem e o ensino são possíveis.

Em todas as cenas de sala de aula a professora coloca em jogo o uso da revista, o uso da linguagem de divulgação científica no ambiente escolar. Ela não institucionaliza conceitos. Ela faz circular a revista e parte do uso da mesma para refletir sobre ela e sua linguagem. Nesse sentido, as perguntas na sala são recorrentes devolvendo às aulas de ciências uma característica inerente a essa área do conhecimento. As situações orais foram fundantes e organizadoras do processo ensinoaprendizagem. Ao falar do artigo, a preocupação das crianças centrase na explicação do conceito presente no artigo. Ressalta-se, por fim, a importância da revista CHC nas aulas de Ciências dado o nível de envolvimento das crianças e da professora, a aprendizagem de conteúdos de ciências e a qualidade da participação de todos durante a experiência pedagógica com o periódico. Entretanto, essa postura não é construída espontaneamente e está relacionada, entre outras coisas, ao acesso à revista na sala de aula e à forma como as atividades de ensino foram conduzidas pela professora. Isso evidencia a escola como lócus de aprendizagem onde os alunos podem descobrir o prazer, a curiosidade e o mistério, escondidos nos textos de divulgação científica. 


\section{REFERÊNCIAS}

ALMEIDA, M. J. P.M. O texto de divulgação científica como recurso didático na mediação do discurso escolar relativo à ciência. In:PINTO. G. A. (org.). Divulgação científica e práticas educativas. Ed. CRV: Curitiba. 2010.

ALMEIDA, M. J. P.M. e ICON, A. E. Divulgação Científica e texto literário - uma perspectiva cultural em aulas de física. Caderno Catarinense de Ensino de Física, v.10, n. 1, p. 7-13, Florianópolis: Universidade Federal de Santa Catarina, 1993.

ALMEIDA, S. A. A. Interações e práticas de letramento mediadas pela revista Ciência Hoje das Crianças em sala de aula. Tese - Universidade de São Paulo, São Paulo, 2011.

ALMEIDA, S. A e GIORDAN, M. A revista Ciência Hoje das Crianças no letramento escolar: a retextualização de artigos de divulgação científica. Educação e Pesquisa. v. 40, n. 4, p. 999- 1014, 2014.

BAKHTIN, M. Estética da Criação Verbal. São Paulo: Martins Fontes, 1992.

BAKHTIN, M. Marxismo e filosofia da linguagem. São Paulo, 8ª ed., Hucitex, 1997.

BRASIL. Secretaria da Educação Fundamental. Parâmetros curriculares nacionais: Ciências Naturais. Brasília: MEC/SEF, 1998.

CUNHA, M. B.; GIORDAN, M. . A divulgação científica como um gênero de discurso: implicações para a sala de aula. In: VII Encontro Nacional de Pesquisa em Educação em Ciências, 2009, Florianópolis. Anais do VII ENPEC. Belo Horizonte: ABRAPEC. v.1. p.1-11, 2009.

CUNHA, M. B. A percepção de ciência e tecnologia dos estudantes de ensino médio e a divulgação científica. 2009. Tese - Universidade de São Paulo, São Paulo, 2009.

CUNHA, M. I. Conta-me agora! As narrativas como alternativas pedagógicas na pesquisa e no ensino. Revista da Faculdade de Educação, São Paulo, v. 23, n. 1-2, jan. 1997.

GINZBURG, C. "Sinais: raízes de um paradigma indiciário" In: GINZBURG, C. Mitos, Emblemas e Sinais: morfologia e história. São Paulo: Cia das Letras, 1991.

GÓES, M. C. R. A abordagem microgenética na matriz histórico-cultural: uma perspectiva para o estudo da constituição da subjetividade. Cad. CEDES. v. 20, n. 50, 2000.

GOUVÊA, G. A Divulgação Científica para Crianças: o caso da Ciência Hoje das Crianças. Tese, Universidade Federal do Rio de Janeiro, 2000.

MARCUSCHI, L. A. Da fala para a escrita: atividades de retextualização. $2^{a}$ ed. São Paulo: Cortez, 2001.

MORTIMER, E.F. Sobre chamas e cristais: a linguagem científica, a linguagem cotidiana e o ensino de Ciências. In: CHASSOT, A. e OLIVEIRA, J. R. (org.). Ciência, Ética e Cultura na educação. São Leopoldo: Unisinos, p.99-118, 1998.

MORTIMER, E. F.; SCOTTT, P. Atividade discursiva nas salas de aula de ciências: uma ferramenta sociocultural para analisar e planejar o ensino. Investigações em Ensino de Ciências, v.7, n. 3, p. 283-306, 2002.

ROJO, R. (org.). Gêneros orais e escritos na escola/tradução e organização. Campinas: Mercado de Letras, 2004. 
ROJO, R. O letramento escolar e os textos da divulgação científica - A apropriação dos gêneros de discurso na Escola. Linguagens em (Dis)curso - v. 8, n. 3, p. 581-612, set/dez. 2008.

SMOLKA, A. L. B. O (im)próprio e o (im)pertinente na apropriação das práticas sociais. Cad. CEDES. v. 20, n. 50, p. 26-40, 2000.

VYGOTSKY, L. S. Formação Social da Mente, São Paulo: Martins Fontes, 1999.

VYGOTSKY, L. Pensamento e linguagem. São Paulo: Martins Fontes, 1991.

\section{NOTAS}

${ }^{1}$ Pesquisa Financiada pela Pró-Reitoria de Pesquisa e Pós-Graduação da Universidade Federal de Ouro Preto (PROPP-UFOP) e Fundação de Amparo à Pesquisa de Minas Gerais (FAPEMIG).

${ }^{2}$ Entrevista realizada com Roxane Rojo. Acesso 16/03/2011. < http// Judite ferreiro asouza. blogspot com/2010/entrevista -com-roxane-rojo-referencia.html >

${ }^{3}$ Disponível no site <http://pontociencia.org.br/experimentos $>$. Esse filme produzido para as crianças trata do pescoço das girafas por meio das teorias de Lamarck e Darwin.

Submetido: 22/12/2016

Aprovado: 02/09/2017

Contato:

Universidade Federal de Ouro Preto

Campus Universitário Morro do Cruzeiro

Ouro Preto $|\mathrm{MG}|$ Brasil

CEP 35.400-000 